are conceived, and how they win or lose acceptance. He rightly points out that science rarely proceeds in an objective, linear fashion. Correct theories are often favoured for the wrong reasons; observations and experiments are frequently misinterpreted; and sometimes force of personality holds sway over analytic reason. Because cosmology has such ambitious goals - to find a coherent explanation for the entire system of things and how it has evolved - these peculiarities are often exaggerated. In particular, cosmology has more than its fair share of eccentric characters, providing ample illustration of the role of personal creativity in scientific progress.

This very well written book conveys the ideas underpinning cosmological theory with great clarity. Taking nothing for granted of his readership, Singh delves into the background of every key scientific idea he discusses. This involves going into the history of astronomical observation, as well as explaining in non-technical language the principles of basic nuclear physics and relativity. The numerous snippets of biographical information are illuminating as well as amusing, and the narrative is driven along by the author's own engaging personality.

As a fan of Singh's previous books, I have to admit that, although this one has many strengths, I found it very disappointing. For one thing, there isn't anything in this book that could be described as new. The book follows a roughly historical thread from pre-classical mythology to the middle of the twentieth century. This is a well-worn path for popular cosmology, and the whole thing is rather formulaic. Each chapter I read gave me the impression that I had read most of it somewhere before. It certainly lacks the ground-breaking character of Fermat's Last Theorem.

The past ten years in cosmology have witnessed a revolution in observation that has, among many other things, convinced us of the existence of dark energy in the Universe. Theory has also changed radically over this period, largely through the introduction of ideas from high-energy physics, such as superstring theory. Indeed, some contemporary Big Bang models bear a remarkable resemblance to the steady-state universe, involving the continuous creation not of mere atoms, but of entire universes.

Frustratingly, virtually all the exciting recent developments are missing from this book, which leaves off just when things started to get interesting, with the COBE satellite in 1992. Readers who want to know what is going on now in this field should definitely look elsewhere. The processes of cosmic discovery and controversy are ongoing, not just relics of the past.

Peter Coles is in the School of Physics and

Astronomy, University of Nottingham,

University Park, Nottingham NG9 2HL, UK.

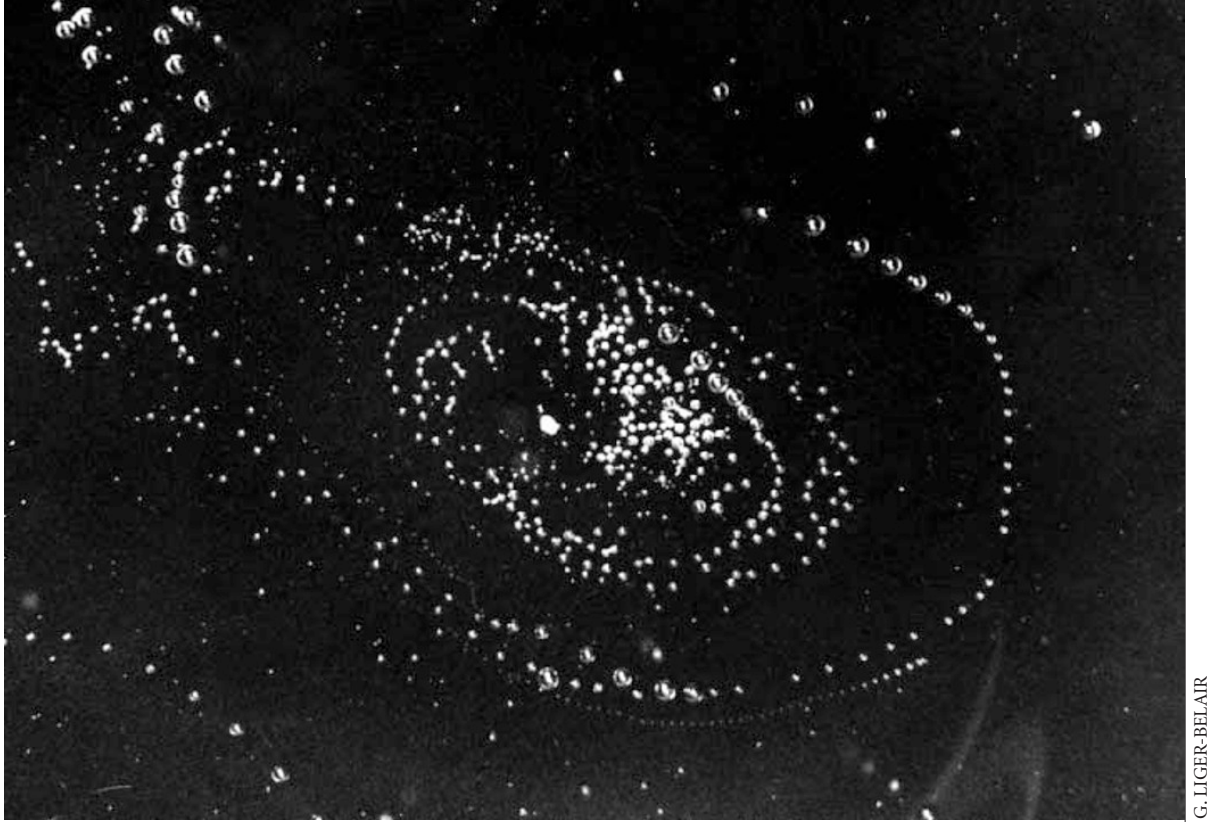

Star quality: bubbles at the surface of champagne arrange into vortices that look like galaxies.

\section{Fizzical attraction}

\section{Uncorked: The Science of \\ Champagne \\ by Gérard Liger-Belair \\ Princeton University Press: 2004. 152 pp. \\ $\$ 19.95, £ 12.95$}

\section{Richard N. Zare}

This book presents the birth, life and death of a champagne bubble with such gusto, good humour and clarity that you will devour its delicious contents in one gulp. Whereas good champagne is to be sipped, this book is not. You will never experience the sensual elegance of champagne in quite the same way again once you have read this entertaining account of its history and 'fizzics'.

The author is associate professor of physical sciences at the University of Rheims Champagne-Ardenne and consultant for the research department of champagne house Moët \& Chandon. He brings to this topic not only great expertise, but also a fine sense of aesthetics, as he shares his striking photographs of how a bubble forms, rises and bursts. These phenomena are often much more complex than we imagine, but Liger-Belair explains bubble science without resorting to a single equation. He succeeds in clarifying for the non-expert such abstruse topics as fluid dynamics, nucleation phenomena, fermentation and the competition between buoyancy and drag. Uncorked provides just enough science to be authoritative and instructive, and carries the reader enthralled from one chapter to another, like a good detective story.

Liger-Belair has made several important original contributions to the science of champagne. For example, he offers photographic proof that bubbles form more on impurities - often fibres that adhere to the walls of the champagne container (a fluted glass, say) - than on microscratches and irregularities in the container walls. These hollow fibres, which act as tiny bubble guns, are deposited on the walls when the champagne flute is dried with a paper towel or cloth. Indeed, without these defects, champagne would not fizz at all. But bursting bubbles are not the only way champagne loses its sparkle. The dissolved carbon dioxide escapes primarily from the liquid surface of the champagne, rather than from the popping of its many tiny bubbles.

Many mysteries are revealed. Why do bubbles rise more rapidly in soda water than in champagne, and more rapidly in champagne than in beer? All three liquids are mostly water and have approximately the same viscosity. For a solution to this riddle, read Uncorked.

For my own taste, I would have preferred the discussion to have stuck to champagne. Instead, the author ends with an afterword on the future of champagne wines, emphasizing the connection of the human production of carbon dioxide to global warming. He concludes with some speculation: It is "not completely unrealistic to think that we eventually may witness the emergence of fine sparkling wines in Great Britain". Climate change deserves its own book, a much larger one of a more serious nature; the emphasis on it seems out of place in this vignette, although Liger-Belair's concern about our effect on the environment is shared by almost all scientists.

Many scientists feel that physical principles are part of our daily lives, not just something to be studied in the laboratory. This book reinforces that belief. It would make an excellent Christmas gift to anyone who wants to learn how a scientist views the world - or to anyone who has ever wondered about the mysterious fluid that has launched so many ships and toasted so many celebrations.

Richard N. Zare is in the Department of Chemistry, Stanford University, Stanford, California 94305, USA. 